the game. The very concept of professionalism is becoming debased in the public mind in that so many professionals have gone beyond their remit, which is largely to do with the maintenance of levels of skill, training and ethical standards, to become exclusively preoccupied with self-defence and preservation of arcane knowledge.

We feel that we are often in a position to be of use to the Royal College and its members. MIND is spending a fair amount of money on running the All-Party Parliamentary Mental Health Group to which the Royal College has good access. We think that some of our literature could be helpful to psychiatrists. Our next new venture is to produce a Mental Health Year Book which will try to overcome some of the problems caused by the official time-lag in making data available and the difficulties we all experience in collating useful information which has to be gleaned from different administrative sources. We hope to run a major conference on treatment later this year.

I feel sure that, just as the Royal College has achieved great advances in improving standards of psychiatric training and in encouraging new and important specialties within psychiatry, it could generate rather more enthusiasm for psychiatry among medical students and young people who are considering entering the medical profession. None of us who are aware of the progress made over the last ten to twenty years in modern psychiatry can be complacent when only 40 per cent of junior psychiatrists are trained within the UK and when the profession cannot produce enough consultants to fill all the important posts available.

We look to the Royal College to provide leadership and a focus for mental health and psychiatric concern. Yet we probably need something more than the Royal College and something more than MIND. During a recent visit to the United States I was tremendously impressed by the National Institute for Mental Health, which seems to have the money and the executive power to provide comprehensive information services and to instigate research and service development. If we suggested something similar here it could easily be dismissed as an alien monstrosity or a quango, but such arguments do not obviate the need.

I hope that you will share with me the view that mental health services, including psychiatry, are in crisis which is largely, but not wholly, the product of administrative and political neglect. Mental health represents by far the largest and most serious health and social problem of our time, given that the legislation, the organization of services, the state of the science and the morale of the professions leave a lot to be desired. What is happening to our society, in economic and social terms, is crudely destructive of good mental health, which can only increase demand for psychiatric services. Should we not all in our separate compartments, professions and organizations be generating a more radical and more urgent response? Should we not collectively be demanding of Government that it either provides the resources for us to do what we know needs to be done or that it recognizes the enormity of the issue and sets up a Royal Commission to educate itself and the public and to provide the impetus and the justification for fundamental reorganization and change?

\title{
Confidentiality: Minors Assessed by Multidisciplinary Teams
}

\author{
Jean Harris, Consultant Psychiatrist, Child and Family Psychiatric Service, Dunstable
}

This article is based on work undertaken at the request of my fellow members of a DHSS Working Party chaired by Professor Norman Tutt, Department of Applied Social Studies at the University of Lancaster. The terms of reference were: 'to consider observation and assessment services for children and young persons referred to local authority Social Services Departments; to clarify the role of observation and assessment centres; to consider the promotion of non-residential observation and assessment; to consider what improvements in present assessment practice might be helpful or necessary and to make recommendations'. The report is currently in its final draft and has been sent to the DHSS for approval; and, since my contribution has necessarily been compressed into a few paragraphs, my colleagues suggested that I should seek an additional route to publication.

In attempting to elaborate this theme, it is not difficult to find references which are tangentially relevant, or which enable the formulation of appropriate questions, but it is less easy to find previously published specific guidelines. This topic may be approached in several ways:

(I) From the standpoint of a multidisciplinary team working (a) in a residential setting supplied with offices, secretarial staff, and telephones, such as a hospital, special school or assessment centre managed by a Department of Social Services; or (b) within a community-based network of services for children.

(II) From the standpoint of (a) a child/client under 18 years of age; or (b) his parents or legal guardians.

The Royal College of Psychiatrists (1977a) has published guidelines which, though meant for psychiatrists working with adult patients in National Health Service settings, 
emphasize relevant modern problems such as photo-copying, extensive documentation, changing legal procedures and security problems. This paper stresses that hospital case records are the property, not of the doctor or of the patient, but of the Secretary of State for Social Services and that any senior official may call for such records which also may be subpoenaed. At the same time the College called for an interdisciplinary working party to inquire into the problems of security, access to and confidentiality of psychiatric case records'. The recommendation, which has been implemented, continues the Working Party should include at least psychiatric nurses, social workers, records officers and patient representatives' (my italics). The College seemingly had not then envisaged a wider brief, that the proposed Working Party should also consider confidentiality in relation to legal minors and in non-NHS settings to which doctors may contribute diagnostic, consultative or advisory skills.

Baldwin et al (1976) and Hall (1979) have discussed the increasingly complex ethical problems related to computer storage and the retrieval of confidential information relevant to epidemiological studies and the provision of NHS resources within a community (problems which in principle equally are relevant to Departments of Education and Social Services, to the judicial system and to doctors providing information to employees of these services). Rowbottom and Bromley (1976) and Rowbottom and Hey (1978), though they do not specifically discuss problems of confidentiality in multidisciplinary teams, lucidly delineate the structural and organizational difficulties which must be tackled as a prerequisite to the establishment of continuing, effective communication between team members. The College (1978), in a further memorandum drawing on the work of Rowbottom and his colleagues, and specifically related to child and adolescent psychiatrists, discusses the high value of multidisciplinary teams and the difficulties experienced by psychiatrists in becoming members of such teams. This memorandum recommends that, in child psychiatric clinics, the psychiatrist should have primacy, both because accountability is more clearly defined and because under such circumstances, confidentiality may be related to the long established, though evolving, medical code. Both the College (1977b and 1978) and Rowbottom and his colleagues (1976 and 1978) stress the importance of clearly delegated responsibility to non-medical members of multidisciplinary teams who are not, like the doctors, in autonomous practice. The College (1978) specifically recommends that, "hierarchal disciplines should decentralize their powers to their members of the teams of the same order as that of the medical profession', as the prerequisite of effective information sharing and decision making.

None of these papers tackles the specific problems of confidentiality in relation to legal minors. The Warnock report (1978) provides some guidance on the compilation and storage of information and the maintenance of confidentiality in settings such as special schools where educationists have prime responsibility for children and adolescents in their care.

The DHSS Working Party (para 1) has within its brief the comparison of multidisciplinary teams based in residential centres with reasonably secure filing systems and 'free floating', community-based assessment services which must work out their own ground rules. These rules will be based on codes of conduct of variable rigour and antiquity, that for doctors, as indicated above, being much the oldest and clearest. The British Association of Social Workers (1977) has published 'guidelines' on confidentiality which include a valuable section on the legal constraints on social workers and other professionals, emphasizing that records are the property of the social worker and his employer, rather than of the client. The Guild of Psychiatric Social Workers (1978) has formulated comparable unpublished guidelines, as are those of the Association of Education Psychologists. It is implicit in these papers, which are unlikely to have been read widely among doctors, that an assessment team managed by social workers or educationists must establish clear guidelines about the storage and dissemination of the information which it collects and about the uses to which such information may be put. Otherwise, those doctors who are used to the security of hospital-based records (though this may be less certain than has been recognized) will be uneasy about working in other settings.

In practice many such difficulties are still to be overcome by continuing discussion, it being borne in mind, as recommended in one or other form of wording by each relevant professional body, that the interests of the child are paramount. The Warnock report fails to grasp the nettle of the complex problems with regard to the storage and transmission of delicate information. Social Services Departments will meet comparable problems as they attempt to establish non-residential assessment services on behalf of children referred to them. The recent enormous literature on the management of child abuse offers prospective signposts to this wider field.

Hallett and Stevenson (1980) offer a discussion, informed by professional practice experience, of the problems arising when such practice is defined and restricted by rules and procedures formulated after public inquiries into child abuse cases. It may be, however, that multidisciplinary teams working in less dramatic circumstances may have problems about sharing information which, because the task is illdefined and less recognizable, may prove yet more troublesome.

There are few relevant publications written primarily from the point of view of parents and children. Page (1977) provides a tentative voice for children in care, as does OkellJones (1978) for abused children. Lacey et al (1979) discuss the current justice/welfare dilemmas regarding children involved with the law, issues relevant to child psychiatrists working alongside social workers with statutory duties. 
Hallek (1980) focuses on the increasing need for psychiatrists in training to become educated about legal issues, alerts psychiatrists to the lack of statutes or precedents regarding the release of confidential information to relatives, and stresses that spouses may wish to use such information in divorce or child custody cases. He draws attention to the expanding rights of children involved in the American mental health system and to the as yet little explored problems of confidentiality in group and family work.

\section{Discussion}

There is currently a wide range of legal and ethical problems relevant to doctors working with minors. At one end is the right of a small child to be protected from physical abuse or avoidable impairment of his social, physical or emotional development, irrespective of his parents' or guardians' wishes-and all professionals would agree that, under defined circumstances the parents' or guardians' right to confidentiality could be set aside. At the other end are the problems of a 16-year-old, able to give personal written consent for medical treatment or the transmission of hospital records, but subject, until the age of 18 years, to a care order held by the local authority which is his legal guardian. An 18-year-old may ask a child psychiatrist to pass on to a probation officer information obtained, four years earlier in the course of family therapy. A local authority, now a child's legal guardian, may ask a doctor for information provided by the child's parents prior to the court hearing which deprived them of their legal rights.

If children have a right to education appropriate to their needs but are ill or handicapped, they may not obtain their rights without the help of doctors as contributors to multidisciplinary teams in non-medical settings. Children involved with the juvenile justice system are often labelled as psychiatrically ill or in need (vaguely) of 'treatment' and may have a right to the informed evaluation by psychiatrists of the complex moral and ethical issues thus arising.

Thus, as acceptable current practice, confidential information may be exchanged between professionals of whatever discipline, with the informed consent of the child or client group concerned. The parents or guardians of a child under the age of 16 years must give consent on his behalf, and they should be involved and consulted wherever possible beyond this age. Particular attention should be given to situations where the local authority is both the guardian of the child and the decision maker on his behalf regarding the dissemination of information about him, and to the many legal anomalies regarding young people aged between 16 and 18 years.
The sharing of information and its evaluation by a team of professionals is often in a child's best interests, and his parents or guardians, together with the child himself should be involved in this process wherever possible, from whatever source services initially are offered. Principles may be overridden when the rights of a child clearly transcend any rights to confidentiality on the part of his parents or guardians.

However, the formulation of seemingly straightforward principles masks complex problems about separate professional codes of variable rigour, legal constraints upon the maintenance of confidentiality, and arrangements about the control, storage, dissemination and reproduction of information which require continuing debate.

\section{REFERENCES}

Baldwin, J., Lepp, J. \& Wing, J. (1976) Confidentiality of psychiatric data in medical information systems. British Journal of Psychiatry, 128, 417-27.

Brmish Association of SOCiAl Workers (1977) Confidentiality in Social Work. BASW, 16 Kent Street, Birmingham BS 6RD.

HALL, Z. M. (1979) The use and misuse of confidential information. Bulletin of the Royal College of Psychiatrists, March, 47-48.

Hallex, S. L. (1980) Law in the Practice of Psychiatry. pp 166, 173, 190-91, 281-84. New York: Plenum.

Hallet, C. \& Stevenson, O. (1980) Child Abuse: Aspects of Interprofessional Co-operation. London: Allen \& Unwin.

LACEY, R., TAYLor, L. \& Bracken, D. (1979) In Whose Best Interests? London: Cobden Trust/MIND.

OKell-Jones, C. (1977) The fate of abused children. In The Challenge of Child Abuse (ed. A.W. Franklin). London: Academic Press.

PAGE, R. et al (eds) (1977) Who Cares? London: National Children's Bureau.

Rowbottom, R. \& BRomley, G. (1976) Future Organisation in Child Guidance and Allied Work. Brunel Institute of Organisation and Social Studies, Uxbridge, Middlesex.

_ \& HEY, A. (1978) Organisation of Services for the Mentally IIl: A Working Paper. Brunel Institute of Organisation and Social Studies, Uxbridge, Middlesex.

Royal College of Psychiatrists (1977a) Confidentiality: A report to Council by the Joint Ethical Working Party of the College. News and Notes, January, 4-8.

- (1977b) The responsibilities of consultants in psychiatry within the National Health Service. Bulletin, September, 4 7.

(1978) The role, responsibilities and work of the child and adolescent psychiatrist. Bulletin, July, 127-31.

WARNOCK, M. (Chairman) (1978) Special Educational Needs. Report on the Committee of Enquiry into the Education of Handicapped Children and Young People. Cmnd 7212 London: HMSO. 